\title{
Evaluation of Pulmonary Function Test in Healthy \& Asthmatic School Children of Delhi
}

\author{
Amrit Bharadwaj ${ }^{1}$, Varun Malhotra² \\ ${ }^{1}$ Department of Physiology, Santosh Medical College, Ghaziabad, Uttar Pradesh, India. \\ 2Department of Physiology, AIIMS, Bhopal, Madhya Pradesh, India.
}

\section{ABSTRACT}

\section{BACKGROUND}

As the incidence of asthma and major lung diseases is on the rise, it is necessary to check the lung function of school going children in major cities which are polluted. We wanted to study and correlate the lung function test and BMI of asthmatic school children and compare the same with that of normal healthy children living in Delhi.

\section{METHODS}

The study group consists of 106 school students living in Delhi from past 6 years. The prevalence of children having asthma is $7.5 \%$. The control group consists of sex and age matched 80 normal healthy individuals, who are school students. 26 individuals were included in the other group. Lung function has been estimated by spirometric method. In addition to expected values by age, gender, height and weight, the spirometer tests real respiratory flow. The following parameters were evaluated-FVC\%- Forced Vital Capacity, FEV 1 \%- Forced Expiratory Volume at First Sec., FEV 1 /FVC- Forced Expiratory Ratio.

\section{RESULTS}

Most students had their pulmonary function less than that predicted by the machine (Table. 2). Four had symptoms of obstructive respiratory picture, 52 had restrictive pattern, 48 had mild restrictive and four moderately restrictive. Those with FEV1/FVC less than $80 \%$ were labelled as obstructive. Those with FVC less than predicted value were labelled by the machine as restrictive.

\section{CONCLUSIONS}

Our findings suggest that exposure to air pollution can lead to a reduction in school children's lung function. Measures to improve air quality/reduce air pollution from industries, vehicles by adopting $\mathrm{CNG} /$ carpool/odd-even-rule, planting trees, pranayama, lifestyle changes etc. cannot be overemphasized here. The Supreme Court recently banned burning crackers in Delhi and burning of stubble.

\section{KEY WORDS}

Pulmonary Lung Function Test, FEV1, FVC, BMI Pollution, School Children

\author{
Corresponding Author: \\ Varun Malhotra, \\ Department of Physiology, \\ AIIMS, Bhopal, \\ Madhya Pradesh, India. \\ E-mail: \\ varun.physiology@aiimsbhopal.edu.in
}

DOI: $10.14260 /$ jemds $/ 2019 / 851$

Financial or Other Competing Interests: None.

How to Cite This Article:

Bharadwaj A, Malhotra V. Evaluation of pulmonary function test in healthy \& asthmatic school children of Delhi. J. Evolution Med. Dent. Sci. 2019;8(52): 3932-3936, DOI: 


\section{BACKGROUND}

According to a World Health Organization survey of 1,600 world cities, air quality in Delhi, India's capital, is the worst in the world.[1],[2] Two other cities in India have lower air quality than Delhi: Gwalior in Madhya Pradesh and Raipur in Chhattisgarh. Anand Vihar is the most polluted area of Delhi. An estimated 1.5 million people are killed each year by air pollution in India; it is India's fifth-largest killer. According to the WHO, India has the highest death rate in the world due to chronic respiratory diseases and asthma. Poor air quality destroys the lungs of 2.2 million or $50 \%$ of all children irreversibly in Delhi. In November 2016, air pollution spiked far beyond acceptable levels in an event known as Delhi's Great Smog. PM 2.5 and PM 10 particulate matter rates reach 999 micrograms per cubic meter, while 60 and 100 respectively are the safe limits for these contaminants.

Motor vehicle emissions are one of the causes of poor air quality. According to some reports, 80 per cent of PM 2.5 air pollution is caused by vehicular traffic, though other reports suggest the percentage is lower.[3] Other causes include wood-burning fires, fires on agricultural land, exhaust from diesel generators, dust from construction sites, and burning garbage. And in Delhi, illegal industrial operation. 2.2 million In Delhi, children suffer irreversible damage to the lungs due to poor air quality. Furthermore, research shows that pollutants may decrease the intelligence quotient of children and increase the risks of autism, diabetes and even adultonset diseases such as multiple sclerosis. Poor air quality causes diminished lung capacity, headaches, sore throats, coughs, tiredness, and early death.

During childhood asthma, when exposed to certain stimuli, such as inhaling airborne pollen or catching a cold or other respiratory infection, the lungs and airways become easily inflamed. Asthma in children can cause irritating regular symptoms that interfere with play, sports, work, and sleep. Unmanaged asthma can cause dangerous attacks of asthma in some children. Childhood asthma is not an adult asthma disease, but children face unique challenges. Asthma in children is a leading cause of admissions, hospitalizations and missed school days to the emergency department. Sadly, there is no cure for childhood asthma, and symptoms can persist into adulthood. But one can keep the symptoms under control and prevent them with the right treatment.

Global Strategy for Asthma Management and Prevention Guidelines define asthma as "a chronic inflammatory disorder of airways associated with increased airway hyperactivity, recurrent wheezing episodes, breathlessness, tightness of the chest, and coughing." Asthma diagnosis is suspected in children with recurrent airflow obstruction episodes characterized by chronic wheeze/recurrent isolated cough/recurrent breathlessness/ chest tightness/nocturnal cough. There may be no indicators at the time of diagnosis that asthma is characteristically episodic. Spirometry and peak flow meter can be used as an aid to diagnosis, provided the child can perform the test. Standard questionnaires have circumvented problems in case description for public assessment of childhood bronchial asthma. The proportion of Indian school children with bronchial asthma has increased over the past 10 years to more than double. When 40 percent of children with insignificant wheeze and 70-90 percent of those with troublesome asthma tend to have symptoms in mid-adult life, the rise in asthma prevalence in children may have serious implications for their adult life. Etiology remains unknown despite research work aimed at understanding why some people and not others experience asthma. Experimental for possible reasons of epidemiological profile heterogeneity may be a more elusive source for clarifying some etiological aspects.

We wanted to study and correlate the lung function test and BMI of asthmatic school children and compare the same with that of normal healthy children living in Delhi.

\section{Hypothesis}

Pulmonary lung function test has a correlation with BMI and the pollution plays an effect in increasing in the development of asthma, increase in severity of asthma, increase the no of asthma attacks per year, no of absent days from school due to asthma.

\section{Null Hypothesis}

Pulmonary lung function test has no correlation with BMI. Pollution has no correlation with asthma in children.

\section{METHODS}

\section{Study Design}

A cross sectional study.

\section{Subjects}

The study group consists of 106 school students living in Delhi for past 6 years. The prevalence of children having asthma is $7.5 \%$. The control group, consist of sex and age matched 80 normal healthy individuals, who are school students. Taking 26 individuals as other group.

\section{Sample Size}

$\mathrm{SS}=\mathrm{Z}^{2} \mathrm{X}(\mathrm{p}) \mathrm{X}(1-\mathrm{p}) / \mathrm{C}^{2}$

Where, $\mathrm{SS}=$ sample size, $\mathrm{Z}=$ value $\mathrm{A}$ (e.g.- 1.96 for a $5 \%$ level of significance), $\mathrm{P}=$ prevalence percentage of children having asthma, expressed in decimal, $\mathrm{C}=0.05$ (confidence level)

\section{Exclusion Criteria}

- Children having previous history and currently having treatment for pulmonary tuberculosis

- Participants having any habit which affects the lungs e.g.smoking.

- Participants having previous history of pneumonia for the last 3 or less months.

- $\quad$ Children having history of silicosis, respiratory distress syndrome.

\section{Inclusion Criteria}

- Age group of 12-16 years for both study group and the control group.

- $\quad$ Studying in the school for greater than or equal to 6 years

- Normal healthy group having no previous history of respiratory disorder were included as controls.

- Participants having past history of asthma due to obstructive lung disease were included as study group. 


\section{Estimation of Lung Function}

Spiro-metric method was used to estimate lung function. In addition to predicted values by age, sex, height and weight, the Spiro meter measures actual respiratory flow. Following parameters were evaluated-

1. FVC\%-forced vital capacity.

2. FEV $1 \%$-forced expiratory volume at first sec.

3. FEV $_{1} / F$ C-forced expiratory Ratio.

\section{Estimation of Height and Weight}

- Height is estimated by a stadiometer in $\mathrm{cm}$.

- Weight is measured by weighing machine in Kg.

\section{Measurement of BMI}

BMI is calculated by using Quetlet's Index-Divide weight in kilograms (Kg) by height in meters and divide the answer by height again to get BMI.

$$
\text { BMI }=\frac{\text { (weight in kilograms ) }}{\text { height in } \text { meters }^{2}}
$$

\section{Statistical Analysis}

The statistical data analysis was based on the estimation of the mean, standard deviation (SD) and the category distribution according to the existence of each variable. The difference between mean values of different variables between school students having asthma and control group has been evaluating by using unpaired students test. Pearson correlation test on the entire data as well as within group is used to test whether lung function tests correlate with BMI.

\section{RESULTS}

Most students had their pulmonary function less than the predicted by the machine (Table. 2). Four had symptoms of obstructive respiratory picture, 52 had restrictive pattern, 48 had mild restrictive and four moderately restrictive. Those with FEV1/FVC less than $80 \%$ were labelled as obstructive. Those with FVC less than predicted value were labelled by the machine as restrictive. Their pulmonary function was correlated with BMI in, Figure 1, and Figure 2. The correlation coefficient and $\mathrm{p}$ values are shown in Table- 2 .

\begin{tabular}{|c|c|}
\hline & Mean \pm SD \\
\hline Age (Year) & $10.7 \pm 0.69$ \\
\hline Height $(\mathrm{Cm})$ & $149.28 \pm 7.70$ \\
\hline Weight $(\mathrm{Kg})$ & $42.92 \pm 11.33$ \\
\hline BMI & $19.07 \pm 3.90$ \\
\hline Table 1. Mean \pm Standard Deviation of Pulmonary Function Test \\
in School Children
\end{tabular}

\begin{tabular}{|c|c|c|c|}
\hline & Predicted & & \% of Predicted \\
\hline FEV & $2.42 \pm 0.32$ & $1.95 \pm 0.38$ & $80.45 \pm 15.32$ \\
\hline FVC & $2.72 \pm 0.38$ & $2.15 \pm 0.44$ & $79.2 \pm 12.7$ \\
\hline FEV1/FVC\% & $84.47 \pm 0.001$ & $89.83 \pm 11.77$ & \\
\hline \multicolumn{4}{|c|}{ Table 2. Mean Standard Deviation of Anthropometric Parameters of } \\
School Children \\
\hline
\end{tabular}

\begin{tabular}{|c|c|c|}
\hline Correlation & Pearson Correlation & Sig. (2-tailed) \\
\hline FEV1 and BMI & $0.204^{*}$ & $0.036^{*}$ \\
\hline FVC and BMI & $0.256^{* *}$ & $0.008^{*}$ \\
\hline FEV1/FVC\% and BMI & -0.156 & 0.111 \\
\hline \multicolumn{2}{|c|}{ Table 3. Correlation Coefficient and Statistical Significance } \\
of Pulmonary Function Tests and BMI \\
\hline Correlation is significant at the 0.05 level (2-tailed). \\
\hline
\end{tabular}

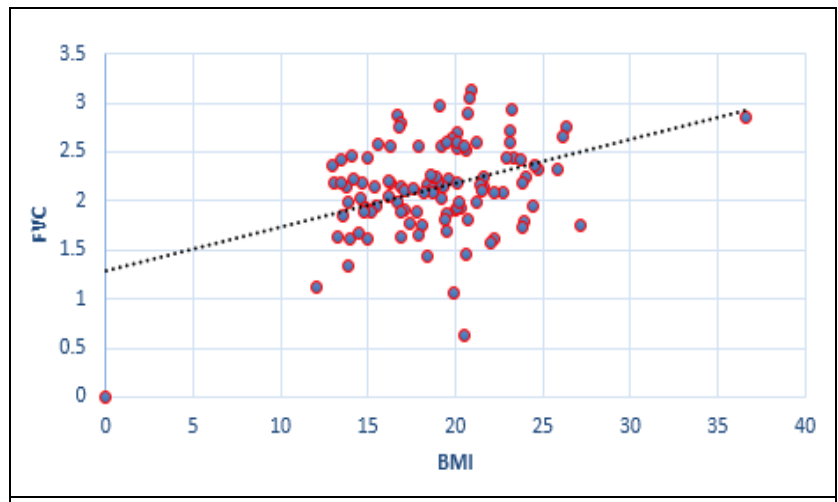

Figure 1. Correlation of FVC and BMI

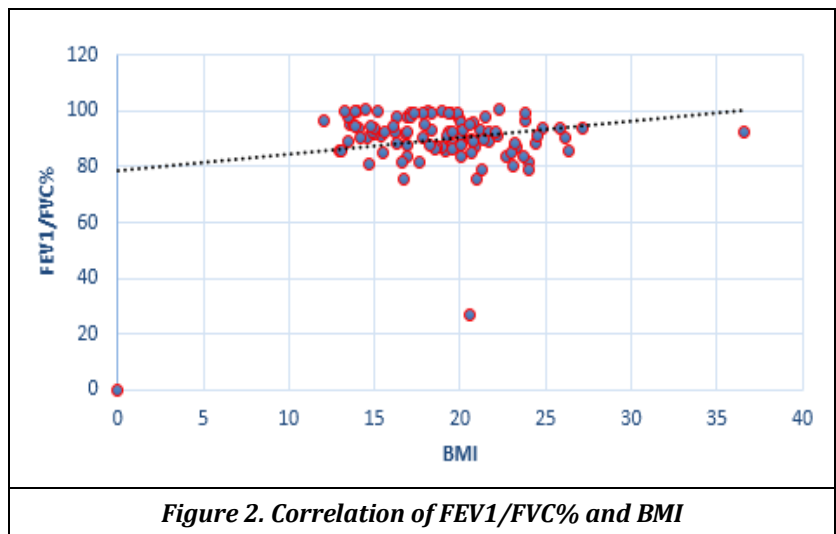

\section{DISCUSSION}

Lung diseases make a significant contribution to mortality. ${ }^{4}$ Children are especially susceptible to the effects of air pollution. We breathe through their ears, bypassing the nasal passage filtering effects, allowing toxins to penetrate deeper into the lungs. Relative to their weight, they have a large surface area and inhale relatively more air than adults.

The results of high FVC in children with high BMI conform to the findings of others. $5,6,7,8$ The reduction in lung volume due to high fat mass cancels the improvement in lung function with elevated BMI likely only in obese children and not in moderately overweight children. Smoking family, genetic predisposition and air pollution have been shown to have a negative impact on the lung function of children.9,10

A relatively new potential risk factor for lower lung function in children is overweight.11-15 Some children's studies show a positive association. ${ }^{16-19}$ rather than an improvement in association ${ }^{20}$ between BMI and FVC and FEV1. Observing different directions of BMI's lung function relationship between adults and children indicates that the adiposity-lung function relation varies with age. Historically, lower FEC and FEV1 in children with high BMI are not found in 8-year-old children. ${ }^{21}$ Wang and his colleagues reported a number of BMI and lung function associations in $11 \mathrm{y}$. A persistently elevated BMI at 12 years of age is not yet associated with lower FVC and FEV1, indicating that at a later stage the transition from the childhood association [High BMI associated with greater lung volume] to the adult association [High BMI associated with smaller lung volume] occurs. Lung function is an objective indicator of respiratory health and a 
predictor of cardiorespiratory morbidity and mortality. ${ }^{22}$ In many cross-sectional and some cohort studies, long-term effects of ambient air pollution on lung functions are investigated. ${ }^{23}$ Oxidative stress and inflammation are hypothesized as the key mechanisms by which environmental air pollution may affect human health. To date, only 2 studies have examined the role of exposure at different time points. Foetal et al. ${ }^{24}$ stated that lung function was correlated with exposure in children 9-10 years of age during the first year of life and lifelong exposure, whereas in the BAMSE cohort, lung function at 8 years of age was associated with exposure in the first year of life, but not with exposure later. Whether boys and girls are sensitive to the effects of air pollution remains unclear. We have not found significant differences in boys' and girls' interaction on clear trends in our sample. Several other researchers reported stronger girls ${ }^{24,25,26}$ associations, while others reported stronger boys ${ }^{27,28}$ associations or no differences. ${ }^{29}$ Our findings suggest that exposure to air pollution can lead to a reduction in school children's lung function. While estimated changes in the parameters of lung function are relatively small, our findings suggest the possibility of clinically relevant decreases in lung function in the entire population.

\section{CONCLUSIONS}

Our findings suggest that exposure to air pollution can lead to a reduction in school children's lung function. Measures to improve air quality/reduce air pollution from industries, vehicles by adopting $\mathrm{CNG}$ /carpool/odd-even-rule, planting trees, pranayama, lifestyle changes etc. cannot be overemphasized here. The Supreme Court recently banned burning crackers in Delhi and burning of stubble.

\section{REFERENCES}

[1] "Ambient [outdoor] air pollution in cities database 2014" WHO. 2014. Retrieved 31 May, 2015.

[2] Harris, Gardiner (14 Feb 2015). "Delhi wakes upto an Air pollution problem it cannot ignore." New York Times. Retrieved 30 May, 2015.

[3] Masoli M, Fabian D, Holt S, et al. Global Institute for Asthma [GINA] program. The global burden of asthma: executive summary of the GINA Dissemination Committee report. Allergy 2004;59(5):469-78.

[4] World Health Statistics. Geneva: World Health Organisation, 2011.

[5] Chu YT, Chen WY, Wang TN, et al. Extreme BMI predicts higher asthma prevalence and is associated with lung function impairment in school-aged children. Pediatr Pulmonol 2009;44(5):472-9.

[6] Perez-Padilla R, Rojas R, Torres V, et al. The empece working $g$ obesity among children residing in Mexico City and its impact on lung function: a comparison with Mexican-Americans. Arch Med Res 2006;37(1):165-71.
[7] Bekkers MB, Wijga $\mathrm{AH}$, de Jongste JC, et al. Waist circumference, BMI and lung function in 8-year old children: the PIAMA birth cohort study. Pediatr Pulmonol 2013;48(7):674-82.

[8] Chen Y, Rennie D, Cormier Y, et al. Waist circumference associated with pulmonary function in children. Pediatr Pulmonol 2009;44(3):216-21.

[9] Eisner MD, Anthonisen N, Coultas D, et al. An official American Thoracic Society public policy statement: Novel risk factors and the global burden of chronic obstructive pulmonary disease. Am J Respir Crit Care Med 2010;182(5):693-718.

[10] Wang X, Wypij D, Gold DR, et al. A longitudinal study of the effects of parental smoking on pulmonary function in children 6-18 years. Am J Respir Crit Care Med 1994;149(6):1420-5.

[11] Jones RL, Nzekwu MM. The effects of body mass index on lung volumes. Chest 2006;130(3):827-33.

[12] Ochs-Balcom HM, Grant BJ, Muti P, et al. Pulmonary function and abdominal adiposity in the general population. Chest 2006;129(4):853-62.

[13] Santana H, Zoico E, Turcato E, et al. Relation between body composition, fat distribution and lung function in elderly men. Am J Clin Nutr 2001;73(4):827-31.

[14] Steele RM, Finucane FM, Griffin SJ, et al. Obesity is associated with altered lung function independently of physical activity and fitness. Obesity (Silver Spring) 2009;17(3):578-84.

[15] Urbilla C, Bustos P, Amigo H, et al. Nutritional status, especially body mass index, from birth to adulthood and lung function in young adulthood. Ann Hum Biol 2008;35(3):322-33.

[16] Chow JS, Leung AS, Li WW, et al. Airway inflammatory and spirometric measurements in obese children. Hong Kong Med J 2009;15(5):346-52.

[17] He QQ, Wong TW, Du L, et al. Respiratory health in overweight and obese Chinese children. Pediatr Pulmonol 2009;44(10):997-1002.

[18] Perez-Padilla R, Rojas R, Torres V, et al. Obesity among children reading in Mexico city and its impact on lung function: a comparison with Mexican-Americans. Arch Med Res 2006;37(1):165-71.

[19] Wang R, Custovic A, Simpson A, et al. Differing associations of BMI and body fat with asthma and lung function in children. Pediatr Pulmonol 2014;49(11):1049-57.

[20] Spathopoulos D, Paraskakis E, Trypsianis G, et al. The effect of obesity on pulmonary lung function of school aged children in Greece. Pediatr Pulmonol 2009;44(3):273-80.

[21] Bekkers MB, Wijga AH, De Jongste JC, et al. Waist circumference, BMI and lung function in 8-year-oldchildren: the PIAMA birth cohort study. Pediatr Pulmonol 2013;48(7):674-82.

[22] Sin DD, Wu L, Man SF. The relationship between reduced lung function and cardiovascular mortality: a population-based study and a systemic review of the literature. Chest 2005;127(6):1952-9.

[23] Gotschi T, Heinrich J, Sunyer J, et al. Long term effects of ambient air pollution on lung function a review. Epidemiology 2008;19(5):690-701. 
[24] Oftedal B, Brunekree B, Nystad W, et al. Residential outdoor air pollution and lung function in school children. Epidemiology 2008;19(1):129-37.

[25] Frey C, Hoelscher B, Cyrys J, et al. Association of lung function with declining ambient air pollution. Environ Health Perspect 2003;111(3):383-7.

[26] Peters JM, Avol E, Gauderman WJ, et al. A study of twelve southern California communities with differing levels and types of air pollution. II. Effects on pulmonary function. Am J Respir Crit Care Med 1999;159(3):768-75.
[27] Schultz E, Gruzieva 0, Bellander T, et al. Traffic related air pollution and lung function in children at 8 years of age- a birth cohort study. Am J Resp Crit Care Med 2012;186(12):1286-91.

[28] Brunekreef B, Janssen NA, de Hartog J, et al. Air pollution from truck traffic and lung function in children living near motorways. Epidemiology 1997;8(3):293-303.

[29] Raizenne M, Neas LM, Damokosh Al, et al. Health effects of acid aerosols on North American children: pulmonary function. Environ Health Perspect 1996;104(5):506-14. 